\title{
Selection of Appropriate Spatial Resolution for the Meteorological Data for Regional Winter Wheat Potential Productivity Simulation in China Based on WheatGrow Model
}

\author{
Xiaohu Zhang, Hao Xu® ${ }^{\circledR}$, Li Jiang ${ }^{\circledR}$, Jianqing Zhao, Wenjun Zuo, Xiaolei Qiu, Yongchao Tian, \\ Weixing Cao and Yan Zhu * (1) \\ Key Laboratory for Crop System Analysis and Decision Making, Ministry of Agriculture and Rural Affairs, PRC, \\ National Engineering and Technology Center for Information Agriculture, Jiangsu Key Laboratory for \\ Information Agriculture, Jiangsu Collaborative Innovation Center for Modern Crop Production, \\ Nanjing Agricultural University, Nanjing 210095, China; zhangxiaohu@njau.edu.cn (X.Z.); \\ HaoXu1989@hotmail.com (H.X.); jiangli_cn@foxmail.com (L.J.); jianqingZ@hotmail.com (J.Z.); \\ zoewenjunzuo@hotmail.com (W.Z.); qiuxiaolei@njau.edu.cn (X.Q.); yctian@njau.edu.cn (Y.T.); \\ caow@njau.edu.cn (W.C.) \\ * Correspondence: yanzhu@njau.edu.cn; Tel.: +86-25-84396598
}

Received: 8 August 2018; Accepted: 18 September 2018; Published: 20 September 2018

\begin{abstract}
The crop model based on physiology and ecology has been widely applied to the simulation of regional potential productivity. By determining the appropriate spatial resolution of meteorological data required for model simulation for different regions, we can reduce the difficulty of acquiring model input data, thereby improving the regional computing efficiency of the model and increasing the model applications. In this study, we investigated the appropriate spatial resolution of meteorological data needed for the regional potential productivity simulation of the WheatGrow model by scale effect index and verify the feasibility of using the landform to obtain the appropriate spatial resolution of meteorological data required by the potential productivity simulation for the winter wheat region of China. The research results indicated that the spatial variation of landforms in the winter wheat region of China is significantly correlated to the spatial variation of multi-year meteorological data. Based on the scale effect index, we can obtain a spatial distribution of appropriate spatial resolution for the meteorological data required for the regional potential productivity simulation of the WheatGrow model for the winter wheat region of China. Moreover, although we can use the spatial heterogeneity of landforms to guide the selection of appropriate spatial resolution for the meteorological data, in the regions where the spatial heterogeneity of the landform is relatively weak or relatively strong over a small range, the method of using a single heterogeneity index derived from semi-variogram cannot well reflect the scale effect of simulation results and needs further improvement.
\end{abstract}

Keywords: WheatGrow model; potential productivity; spatial resolution; spatial heterogeneity; semi-variogram analysis

\section{Introduction}

The potential productivity is the maximum production capacity of a variety when grown in environments to which it is adapted, with nutrients and water nonlimiting and with pests, diseases, weeds, lodging, and other stresses effectively controlled [1]. Regional potential productivity simulation can estimate characteristics of variation in the spatiotemporal distribution of crop productivity 
potential, identify the rule of variation in the upper limit of yield, optimize the planting system, and improve the use efficiency of agroclimatic resources, thereby providing a scientific reference for regional sustainable development [2,3]. At present, the simulation of the regional potential productivity of crops includes two methods: the empirical model and the mechanical model. The empirical model, often used includes the agro-ecological region method (AEZ) recommended by the United Nations Food and Agriculture Organization (FAO) [4,5]. However, the empirical model, which establishes a simple statistical equation based on statistical data, does not consider the genetic characteristics and growth and development of crops, and the interpretation and universality is relatively poor. The mechanical model is based on the eco-physiological process of crop growth and is a powerful tool to predict crop yield, manage agricultural resources, and assess the influence of climate change on agricultural production, and is most widely applied in the regional potential productivity simulation [6]. At present, the CERES-WHEAT model $[7,8]$ WOFOST model $[9,10]$ and WheatGrow model $[11,12]$ of wheat growth have been applied to the simulation of the regional potential productivity in China.

However, the lack of high-quality spatial input data is the main problem for the regional simulation of the crop model [13]. One important method to solve this problem is to couple the crop model and GIS and use the spatial interpolation method to interpolate the station data of the model into a grid surface. Moreover, every homogeneous pixel (grid) is taken as a simulation unit for the model calculation, and therefore, the regional simulation yield is obtained [14]. As the model input data have spatial heterogeneity, using high spatial-resolution data will increase the difficulty of data acquisition and reduce the computational efficiency of the model $[15,16]$. Therefore, the issue of input data needs to be solved in the regional application of the crop model to analyze the scale effect of the simulation results and to determine the appropriate spatial resolution of the model input data based on the model input data of different spatial resolutions.

Meteorological data are the main input data for the regional potential productivity simulation. The use of high spatial resolution meteorological data for the regional potential productivity simulation can reflect more spatial details and ensure simulation accuracy, but increase the model computation and data storage. However, the use of low spatial resolution meteorological data will cause the loss of data information. Moreover, the stronger the spatial heterogeneity of meteorological data is, the more significant the loss of data information will be, which can cause a reduction in simulation accuracy [15-20]. Therefore, it has been widely suggested to study the influence of meteorological data with different spatial resolutions on the regional potential productivity simulation and to select the appropriate spatial resolution of meteorological data for the model simulation. Previous studies have conducted relevant regional studies and constructed a strategy to guide the selection of appropriate spatial resolution for meteorological data based on the spatial heterogeneity of landforms [15,16,21-23]. The winter wheat region of China is vast, and the climate conditions and ecological conditions are complicated. The WheatGrow model is the primary model for the simulation of potential productivity. Relevant studies on the influence of meteorological data with different spatial resolutions on the regional potential productivity simulation of the WheatGrow model have not been conducted, and the relationship between the spatial heterogeneity of landforms and the appropriate spatial resolution of the meteorological data has not been studied.

In this study, we take the winter wheat region of China as the research area and construct the multi-spatial resolution meteorological data. We use the WheatGrow model to simulate the regional potential productivity and construct the scale effect index to analyze the scale effect of simulation results. Moreover, we use the threshold of the scale effect index to determine the appropriate spatial resolution of the meteorological data needed for the simulation of potential productivity in the winter wheat region of China. Finally, we combine the relationship between the spatial heterogeneity of the landform and the scale effect index and investigate the feasibility of using the spatial heterogeneity of landforms to acquire the appropriate spatial resolution of meteorological data required for the potential productivity simulation in the winter wheat region of China. 
This paper is organized into four parts. The material section (Section 2) describes the geographic overview of the research area and introduces the simulation model of crop growth used in this study, the data source, and the preconditioning. The method section (Section 2) describes the construction method of the scale effect index, the selection method for the appropriate spatial resolution of the meteorological data, and the method to analyze the spatial heterogeneity of the landform. The results and discussion section (Section 3) presents the simulation results for different spatial resolutions in the research area and the spatial distribution for the appropriate spatial resolution of meteorological data and the investigation on the relationship between the scale effect of the simulation results and the spatial heterogeneity of the landform. This section also investigates the feasibility of selecting the appropriate spatial resolution of meteorological data based on the spatial heterogeneity of the landform. Finally, we present the conclusions obtained by this study (Section 4).

\section{Materials and Methods}

\subsection{Research Area}

In this study, we took the winter wheat region of China as the research area (Figure 1a). The winter wheat region of China $\left(102^{\circ} 46^{\prime}-122^{\circ} 11^{\prime} \mathrm{E}, 28^{\circ} 13^{\prime}-41^{\circ} 10^{\prime} \mathrm{N}\right)$ is the main production area of winter wheat in China. The region was divided into four sub-regions: The north winter wheat sub-region (NS), the Huang-Huai winter wheat sub-region (HHS), the middle-lower reaches of the Yangzi River winter wheat sub-region (MYS) and the southwest winter wheat sub-region (SWS) (Figure 1b). There were various climate types, including a middle temperature semiarid zone, a middle temperate semi-humid zone, a warm temperate semi-humid zone, a warm temperate semi-arid region, a north subtropical humid region, and a middle subtropical humid region [24]. The regional spatial distributions of light and temperature resource conditions and terrain have strong characteristics of spatial variability (Figure 1c-e), and the difference in temperature and precipitation was relatively significant. In particular, the annual average temperature in the NS and HHS is $9-15{ }^{\circ} \mathrm{C}$, and the annual precipitation was $440-980 \mathrm{~mm}$; the annual average temperature in the MYS and SWS was $16-25^{\circ} \mathrm{C}$, and the annual precipitation was typically above $1000 \mathrm{~mm}$ [25]. The landforms in the winter wheat region include plains, hills, mountains, and basins, and the difference between the elevation in the east and west was significant. The highest elevation was $5174 \mathrm{~m}$, and the lowest elevation was $-142 \mathrm{~m}$ (Figure 1c).

\subsection{WheatGrow Model}

The process-based WheatGrow model has been widely applied to regional potential productivity simulations in China [11,12,26]. This model includes five sub-models: Apical development and phenology [27-29]; photosynthesis and dry matter production [12]; material distribution and organogenesis [27,30]; yield and quality formation [31,32]; and soil moisture and nutrient balance $[33,34]$. The model runs at a daily time step, simulating wheat growth and development under potential production, water-limited and nitrogen-limited scenarios $[31,35]$. The WheatGrow model has been validated through simulation at multiple eco-sites and under different scales in the main yield region of winter wheat in China, and the results indicate that this model can simulate and predict the growth and development of wheat and the yield formation $[36,37]$. 

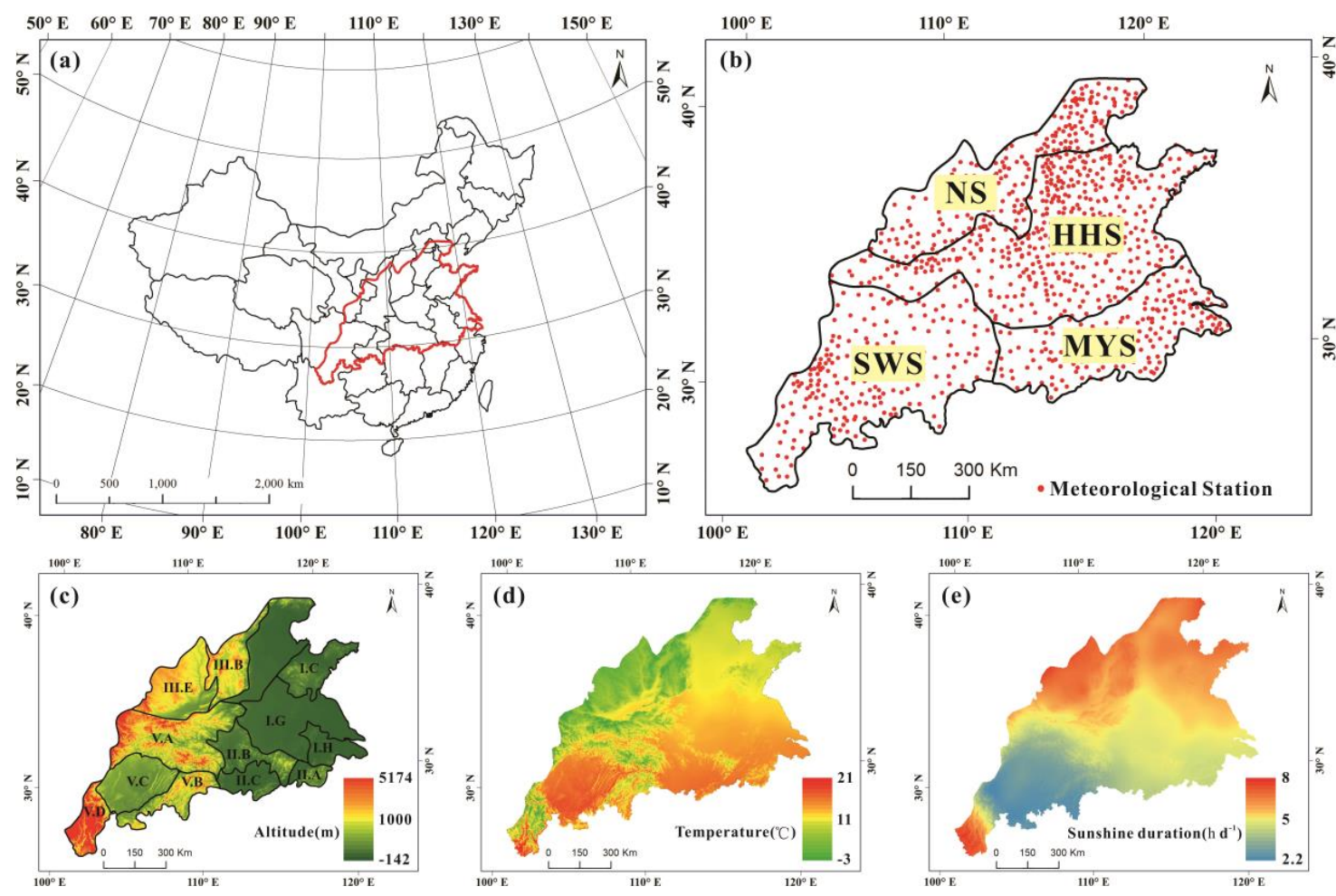

Figure 1. Overview of the research area: Geographic location and distribution of the sub-regions and the meteorological stations (a,b), digital elevation (c), 2000-2009 daily average temperatures (d), average hours of sunshine in 2000-2009 (e). SWS: Southwest winter wheat sub-region; NS: North winter wheat sub-region; HHS: Huang-Huai winter wheat sub-region; MYS: Middle-lower reaches of the Yangzi River winter wheat sub-region; IC: Ludong low hills; IG: Southern and eastern China plains; IH: Ning town hilly plains; IIA: Zhejiang-Fujian middle mountains; IIB: Huaiyang low mountains; IIC: Middle reaches of the Yangzi River hilly plains; IIIB: Shanxi middle mountains and basins; IIIE: Loess Plateau; VA: Qinling-Daba subalpine mountains; VB: Hubei-Guizhou-Yunnan middle mountains; VC: Sichuan basin; VD: southwest Sichuan-Central Yunnan subalpine mountains and basins.

\subsection{Data Description}

The simulation of potential productivity is not subject to the restriction of water, nitrogen, and soil conditions, and is only subject to the influence of weather, variety parameters, and sowing date [38-40]. The meteorological data include daily maximum temperature (Tmax), daily minimum temperature (Tmin), and sunshine duration (SSD). The daily data at 982 meteorological stations in the winter wheat area during 2000-2009 were obtained through the meteorological scientific data sharing service of China Meteorological Administration (http://cdc.nmic.cn/home.do) (Figure 1b). We used the ANUSPLIN local thin plate smooth spline method to interpolate the daily meteorological data in the research area into the multi-resolution grid data [41]. By using the resolution range from $1 \mathrm{~km}$ to $200 \mathrm{~km}$ adopted in previous studies $[15,18,42]$, we constructed the nested sequence of spatial resolution $l_{i}(i=0,1,2,3,4,5)$ as $l_{0}=5 \mathrm{~km}, l_{1}=10 \mathrm{~km}, l_{2}=20 \mathrm{~km}, l_{3}=40 \mathrm{~km}, l_{4}=80 \mathrm{~km}$, and $l_{5}=160 \mathrm{~km}$. To restrict the influence of variety parameters and sowing date on this study, our study uses the same set of variety parameters of the regional typical winter wheat (Triticum aestivum L.) cultivar Ningmai 13 (Table 1) and sets the sowing date uniformly as the 261st day of every year [15]. The terrain data in the study adopt the SRTMGL1_003 DEM data with a spatial resolution of $30 \mathrm{~m}$ [43]. Moreover, we use the NEAREST (nearest neighbor assignment) grid re-sampling method to obtain the DEM data with a spatial resolution of $l_{0}[44]$. 
Table 1. Variety parameters adopted by the WheatGrow model in this study.

\begin{tabular}{cccc}
\hline Name & Description & Unit & Value \\
\hline PVT & Physiological vernalization time & $\mathrm{d}$ & 12 \\
IE & Intrinsic earliness & - & 0.85 \\
PS & Photoperiod sensitivity & - & 0.0008 \\
TS & Temperature sensitivity & - & 1.1 \\
FDF & Filling duration factor & - & 0.8 \\
HI & Harvest index & - & 0.42 \\
LT & Thermal time between two successive leaf tip appearances & ${ }^{\circ} \mathrm{C} \cdot \mathrm{d}$ & 66 \\
GW & 1000-grain weight & $\mathrm{g}$ & 39.3 \\
SLA & Specific leaf area under optimum conditions & $\mathrm{ha} \mathrm{kg}^{-1}$ & 0.002 \\
TA & Tilling ability & - & 0.87 \\
\hline
\end{tabular}

\subsection{General Workflow of Analysis}

In this study, by constructing the scale effect index S, we analyze the influence of meteorological data with six spatial resolutions on the regional potential productivity simulation of WheatGrow in the winter wheat area of China over 10 years (2000-2009) and adopt the threshold of the scale effect index $\mathrm{S}$ to determine the appropriate spatial resolution ASRS of the meteorological data required for the regional potential productivity simulation in the research area. Meanwhile, we analyze the semi-variogram of the DEM and use the relationship between the scale effect index $\mathrm{S}$ and the sill value $\sigma$ of the DEM semi-variogram to obtain the appropriate spatial resolution $\mathrm{ASR}^{\complement}$ of meteorological data based on the spatial heterogeneity of the landform. With the range of semi-variogram, we also compare the results of the two methods and evaluate the influence of landform spatial heterogeneity on the distribution of regional light and temperature resources as well as the effect and feasibility of using the spatial heterogeneity of the landform to obtain the appropriate spatial resolution of meteorological data required for the regional potential productivity simulation of WheatGrow (Figure 2).

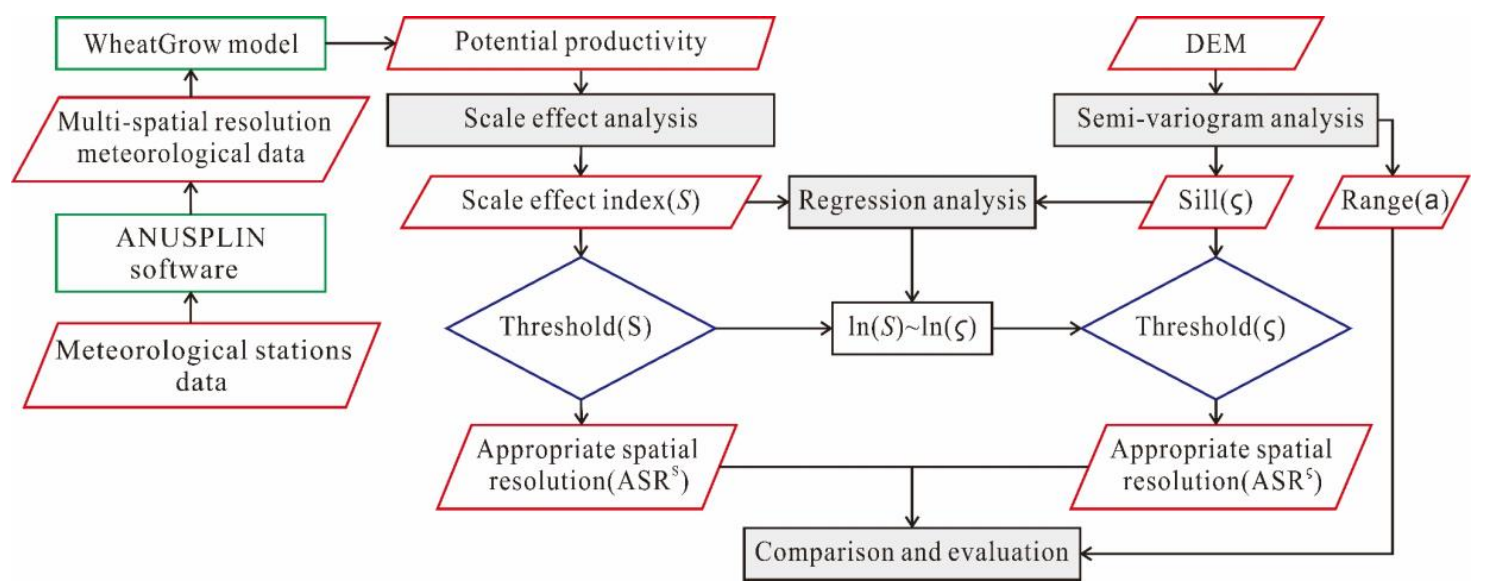

Figure 2. Workflow of analysis.

\subsection{Construction of the Scale Effect Index}

In this study, based on the method of spatial gradient analysis, we designed the scale effect index $S$ with the statistical root-mean-square error (RMSE) between the pixels of different spatial resolutions as the basis [45] and quantitatively reflect the difference between the simulation results of spatial resolution $l_{i}(i>0)$ and the highest spatial resolution $l_{0}$ caused by the change in the spatial resolution of the meteorological data. The scale effect index $S$ is shown in Equation (1):

$$
S=\left(n^{-1} \sum_{c=1}^{n}{\overline{\Delta Y_{c}}}^{2}\right)^{1 / 2}
$$


where $n$ is the number of pixels with spatial resolution $l_{0}$ contained in one pixel of meteorological data with spatial resolution $l_{i}(i>0)$.

$$
\overline{\Delta Y_{c}}=\overline{Y L}-\overline{Y H_{c}}
$$

$\overline{Y L}$ and $\overline{Y H_{c}}$, respectively, represent the 10-year average value of simulation results with spatial resolutions of $l_{i}(i>0)$ and $l_{0}$ for the meteorological data,

$$
\begin{gathered}
\overline{Y L}=\left(\sum_{y=1}^{y=10} Y L_{y}\right) / 10 \\
\overline{Y H_{c}}=\left(\sum_{y=1}^{y=10} Y H_{c, y}\right) / 10
\end{gathered}
$$

$Y L_{y}$ and $Y H_{c, y}$ represent the simulation results of regional potential productivity in the $y$ th year.

$$
\begin{gathered}
Y L_{y}=f\left(W_{l_{i}, y}\right)(i>0) \\
Y H_{c, y}=f\left(W_{l_{0}, y}\right)
\end{gathered}
$$

where $f$ represents the crop model, $Y L_{y}$ represents the simulation result obtained using the meteorological data $W_{l_{i}, y}(i>0)$ with spatial resolution $l_{i}(i>0)$ in the $y$ th year, and $Y H_{c, y}$ represents the simulation results obtained using the meteorological data $W_{l_{0}, y}$ with spatial resolution $l_{0}$ in the $y$ th year.

\subsection{Analysis of the Characteristics of Terrain Spatial Variation Based on the Semi-Variogram}

The landform is an important factor that affects the simulation of the regional potential productivity of crops $[46,47]$. The expression of terrain data has relatively strong characteristics of scale dependence, and its spatial heterogeneity has a significant influence on the scale effect for the simulation results of regional potential productivity [15]. In this study, we analyzed the semi-variogram of the DEM and use the sill value $\varsigma$ of the semi-variogram to characterize the spatial heterogeneity of the landform [48].

The semi-variogram $\gamma(h)$ is the function used to evaluate the autocorrelation of the spatial process and is defined as half of the variance for the difference in regional variable $Z(x)$ at points $x$ and $x+h$, $Z(x)$ and $Z(x+h)$ :

$$
\gamma(h)=\frac{1}{2 N(h)} \sum_{i=1}^{N(h)}\left[Z\left(x_{i}\right)-Z\left(x_{i}+h\right)\right]^{2}
$$

There are several theoretical models of semi-variogram including Spherical, Exponential, Gaussian, etc. [49]. In this study, the DEM semi-variogram is fitted with the spherical model and the spatial distribution of the pixel values was assumed isotropic $[15,50,51]$. The Spherical model is as follows:

$$
\gamma(h)=\left\{\begin{array}{lr}
C_{0} & h=0 \\
C_{0}+C\left(\frac{3 h}{2 a}-\frac{h^{3}}{2 a^{3}}\right) & 0<h \leq a \\
\varsigma & h>a
\end{array}\right.
$$

where $C_{0}$ is the nugget constant; $\varsigma=C_{0}+C$ is the sill value of the semi-variogram, where the larger the value of $\zeta$ is, the stronger the spatial variability of the landform; $a$ is the range, namely, the distance for the value of the DEM semi-variogram to reach the sill value; and $h$ is the distance [49]. When the samples are located on a regular grid, the distance between two points should be smaller than half the grid extent to ensure the significance of the semi-variogram [52]. So in this study, the maximum distance to compute the semi-variogram was set to $1 / 3$ of the grid extent when the spatial resolution is $l_{i}(i>2)[52,53]$. Because the DEM with spatial resolution $l_{0}$ nested in each grid is relatively few when 
the spatial resolution is $l_{i}(i=1,2)$, the maximum distance was respectively set to $10 \mathrm{~km}$ and $20 \mathrm{~km}$ to fit the semi-variogram properly.

\subsection{Selection of Appropriate Spatial Resolution for the Meteorological Data of Regional Potential Productivity Simulation}

In this study, we adopted the scale effect index $S$ and the sill value $\varsigma$ of the DEM semi-variogram to quantitatively reflect the influence of the spatial resolution of the meteorological data on the simulation results. To use the multi-spatial resolution data fusion method to obtain the spatial distribution for the appropriate spatial resolution of meteorological data, in this study, we set the threshold for the scale effect index $S\left(l_{i}\right)(i>0)$ of the simulation results with spatial resolution $l_{i}(i>0)$ to be $t$. If $S\left(l_{i}\right) \leq t$, in comparison with using the data with spatial resolution $l_{i}(i>0)$, the application of meteorological data with spatial resolution $l_{0}$ has limited capability to increase the accuracy of regional potential productivity simulation. We can use the grid with spatial resolution $l_{i}(i>0)$ to replace the grid with spatial resolution $l_{0}$ for the regional potential productivity simulation and therefore reduce the computational load of the model when the spatial resolution $l_{i}(i>0)$ is the appropriate spatial resolution. If $S\left(l_{i}\right)>t$, we abandon the replacement operation. The value of $i$ successively traverses from 1 to 5 , and eventually, we can obtain the appropriate spatial resolution $\mathrm{ASR}^{S}$ of meteorological data required by the regional potential productivity simulation.

Meanwhile, taking the grid with spatial resolution $l_{i}(i>0)$ in the research area as the region, we analyzed the semi-variogram of the DEM with spatial resolution $l_{0}$ nested in each grid and eventually obtain the spatial distribution for the sill value $\varsigma$ of the DEM semi-variogram with spatial resolution $l_{i}(i>0)$. Under spatial resolution $l_{i}(i>0)$, we fit the relationship $\ln (S) \sim \ln (\zeta)$ between the natural logarithmic value of the sill value $\varsigma$ of the DEM semi-variogram and the scale effect index $S$. Therefore, according to the threshold of scale effect index $S$, we can obtain the threshold for the sill value $\varsigma$ of the DEM semi-variogram. By adopting the aforementioned method, we can obtain the appropriate spatial resolution $\mathrm{ASR}^{\sigma}$ of the meteorological data based on the threshold for the sill value $\varsigma$ of the DEM semi-variogram.

\section{Results and Discussion}

In this study, we used the WheatGrow model to obtain the simulation results of potential productivity during the 2000-2009 seasons for the winter wheat region of China (Figure 3). The regional difference in the simulation results of potential productivity is significant. The average level of potential productivity in the NS and HHS is relatively high: $8660.7 \mathrm{~kg} \mathrm{ha}^{-1}$ year $^{-1}$ (Figure $4 \mathrm{~b}$ ) and $8229.2 \mathrm{~kg}^{-}$ $\mathrm{ha}^{-1}$ year $^{-1}$, respectively (Figure $4 \mathrm{c}$ ). The high value regions are primarily distributed in the regions of the Loess Plateau, Shanxi middle mountains and basins, and Ludong low hills (Figure 1c), followed by the MYS and the SWS. The productivity is $7673.6 \mathrm{~kg} \mathrm{ha}^{-1}$ year $^{-1}$ in the MYS (Figure $4 \mathrm{~d}$ ) and $7612.2 \mathrm{~kg} \mathrm{ha}^{-1}$ year $^{-1}$ in the SWS (Figure $4 \mathrm{a}$ ). The high-value areas are distributed in the regions of the southwest Sichuan-Central Yunnan subalpine mountains and basins and Qinling-Daba subalpine mountains, and the low values are distributed in the regions of the Sichuan basin and middle reaches of the Yangzi River hilly plains (Figure 1c).

In addition, the simulation results of different spatial resolutions have a significant scale effect. As the spatial resolution changes, the spatial trend of the simulation results is essentially consistent, but the difference in the spatial details of the simulation results is obvious (Figure 3). As the spatial resolution of the meteorological data decreases, the maximum and minimum of the simulation results decrease, and the variation in the distribution difference of the simulation results is significant. In particular, the effect is most obvious in the SWS, NS, and HS (Figure 4). 
(a)

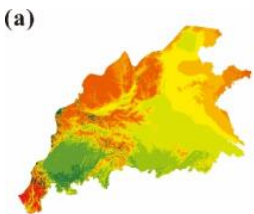

(f) (b)

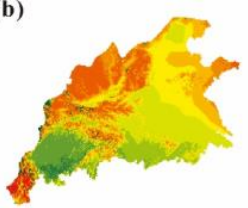

(c)

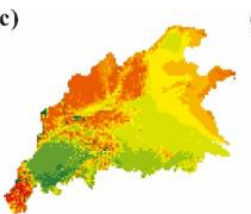

(d)

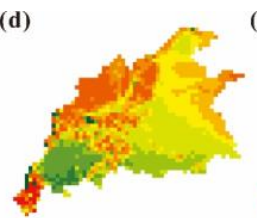

(e)

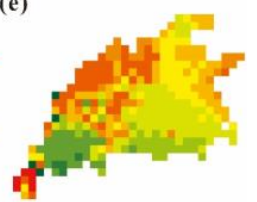

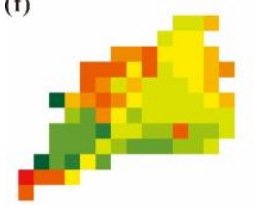

$\begin{array}{lllllllll}4000 & 6000 & 7000 & 7500 & 8000 & 8200 & 8600 & 9000 & 10000\end{array}$

$\stackrel{N}{\stackrel{0}{\longmapsto}} \stackrel{250}{+} 500 \mathrm{~km}$

Productivity $\left(\mathrm{kg} \mathrm{ha}^{-1}\right.$ year $\left.^{-1}\right)$

Figure 3. Spatial distribution of multi-resolution potential productivity simulation results in the research area: the spatial resolution is $5 \mathrm{~km}(\mathbf{a}), 10 \mathrm{~km}(\mathbf{b}), 20 \mathrm{~km}(\mathbf{c}), 40 \mathrm{~km}(\mathbf{d}), 80 \mathrm{~km}(\mathbf{e})$, and $160 \mathrm{~km}(\mathbf{f})$.

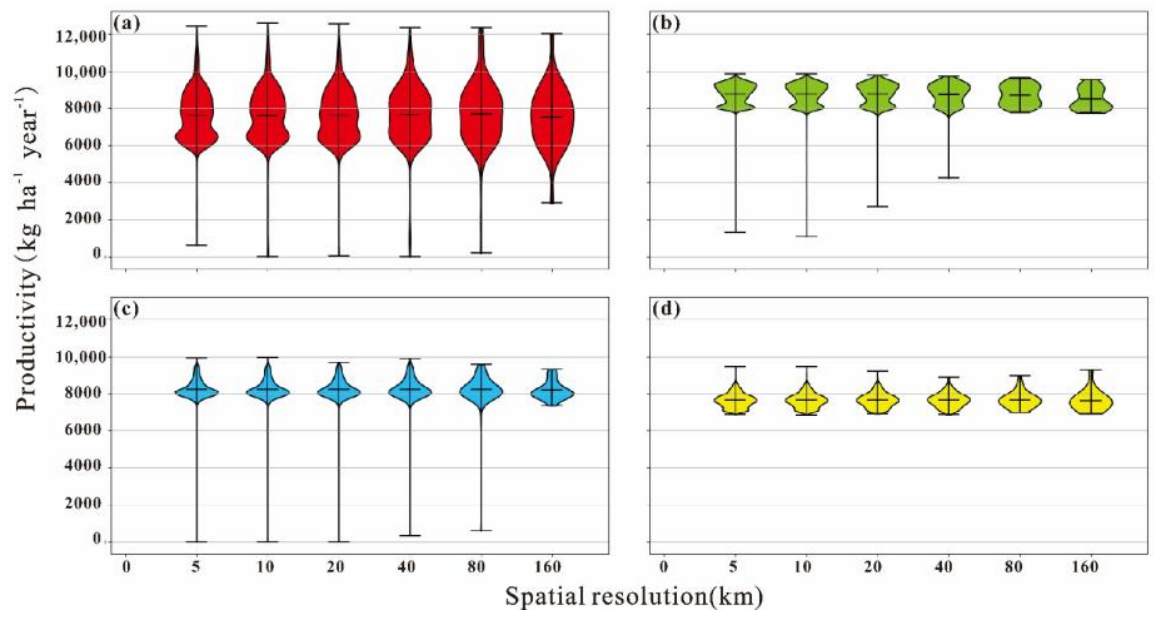

Figure 4. Frequency distribution of regional potential productivity simulation results under various spatial resolutions: southwest winter wheat sub-region (SWS) (a), north winter wheat sub-region (NS) (b), Huang-Huai winter wheat sub-region (HHS) (c), and middle-lower reaches of the Yangzi River winter wheat sub-region (MYS) (d). The upper line, middle line, and lower line in the frequency distribution plot represent the maximum, mean, and minimum of the simulation results, respectively.

\subsection{Selection of Appropriate Spatial Resolution Based on the Scale Effect Index}

The spatial difference in the scale effect index $S$ of the simulation results with different spatial resolutions is significant (Figure 5). The high values are primarily distributed in the regions with relatively strong spatial heterogeneity of landforms in the west of the research area, and the low values are primarily distributed in the eastern plains area. With the scale effect index $S$ using the spatial resolution of $20 \mathrm{~km}$ as an example, the highest value that can be reached is $\mathrm{e}^{9.04} \approx 8433.8 \mathrm{~kg} \mathrm{ha}^{-1}$ year $^{-1}$, and the lowest value is only $\mathrm{e}^{1.1} \approx 3 \mathrm{~kg} \mathrm{ha}^{-1}$ year $^{-1}$. Furthermore, in the eastern plains area, the scale effect index $S$ has the trend of gradually increasing as the spatial resolution of meteorological data declines.

(a)

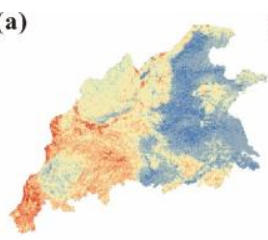

(b)

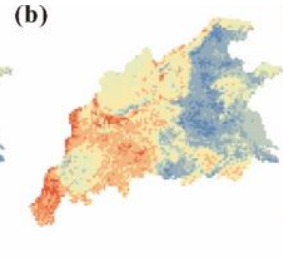

(c)

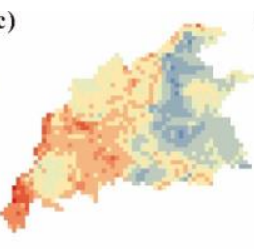

(d)

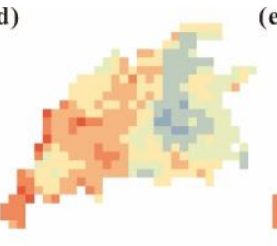

(e)

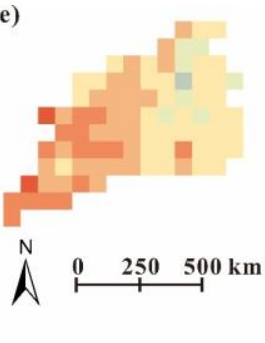

Figure 5. Spatial distribution of the scale effect index $S$ : The spatial resolution is $10 \mathrm{~km}(\mathbf{a}), 20 \mathrm{~km}(\mathbf{b})$, $40 \mathrm{~km}(\mathbf{c}), 80 \mathrm{~km}(\mathbf{d})$, and $160 \mathrm{~km}(\mathbf{e})$. 
We set the threshold of the scale effect index $S$ as $100 \mathrm{~kg} \mathrm{ha}^{-1}$ year $^{-1}, 200 \mathrm{~kg} \mathrm{ha}^{-1}$ year $^{-1}, 300 \mathrm{~kg}$ $\mathrm{ha}^{-1}$ year $^{-1}$, and $400 \mathrm{~kg} \mathrm{ha}^{-1}$ year $^{-1}$ and obtained the appropriate spatial resolution of meteorological data required for the regional potential productivity simulation of WheatGrow (Figure 6). The spatial resolution of data needed for the plains area in the east region of the research area is relatively low and is concentrated at $80 \mathrm{~km}$ and $160 \mathrm{~km}$; the spatial resolution of data needed in the western and southwestern mountainous regions is relatively high, and is $5 \mathrm{~km}$ in most regions. As the threshold of scale effect index $S$ increases, the spatial resolution in the most eastern plains area declines to $160 \mathrm{~km}$ and is maintained at $5 \mathrm{~km}$ in most regions with relatively strong spatial heterogeneity of landforms in the SWS.

(a)

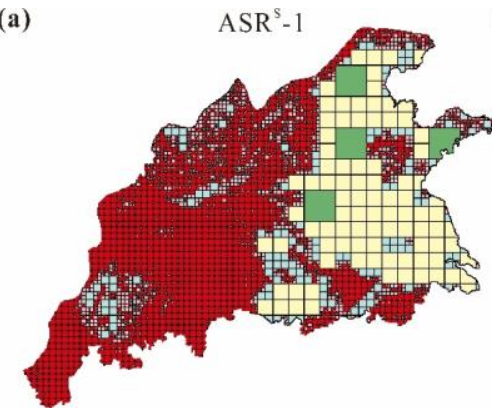

(c)

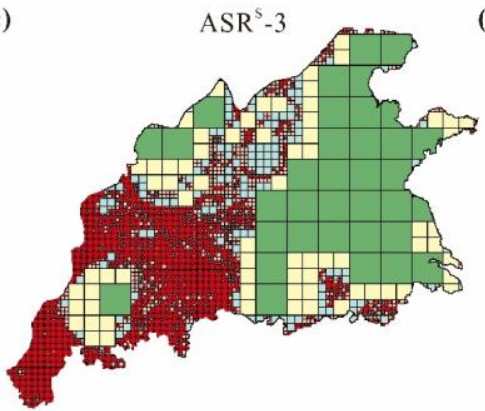

(b)

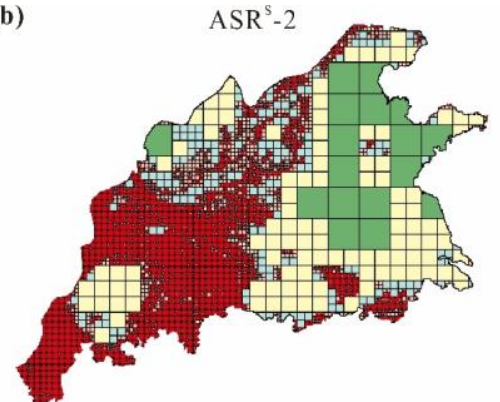

(d)

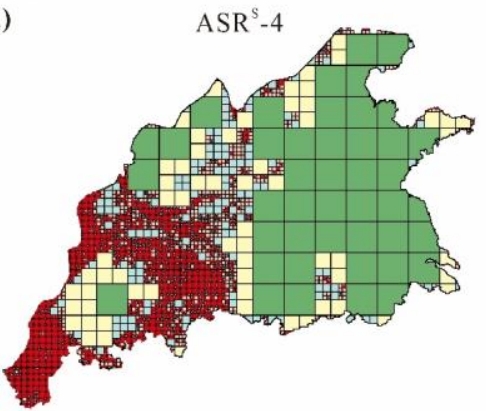

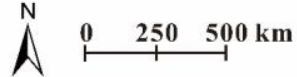

Spatial resolution $(\mathrm{km})$

$\square 160$

$\square 80$

$\square 40$

$\square 20$

10

5

Figure 6. Appropriate spatial resolution of meteorological data for the regional potential productivity simulation based on the scale effect index: Appropriate spatial resolution ASR $^{S}-1$ for the threshold of the scale effect index $S$ of $100 \mathrm{~kg} \mathrm{ha}^{-1} \operatorname{year}^{-1}$ (a); appropriate spatial resolution $\mathrm{ASR}^{S}-2$ for the threshold of the scale effect index $S$ of $200 \mathrm{~kg} \mathrm{ha}^{-1}$ year $^{-1}$ (b); appropriate spatial resolution $\mathrm{ASR}^{S}-3$ for the threshold of the scale effect index $S$ of $300 \mathrm{~kg} \mathrm{ha}^{-1}$ year $^{-1}$ (c); and appropriate spatial resolution $\mathrm{ASR}^{S}-4$ for the threshold of the scale effect index $S$ of $400 \mathrm{~kg} \mathrm{ha}^{-1}$ year $^{-1}(\mathrm{~d})$.

The main purpose of this study was to construct the scale effect index $S$ and to obtain the appropriate spatial resolution of meteorological data for the simulation of regional potential productivity in the winter wheat region of China in the allowed error range. Therefore, we can use the appropriate spatial resolution to effectively reduce the computations required by the model and decrease the difficulty in obtaining high-accuracy model input spatial data. In the regional application of the crop model, every grid is the basic simulation unit, and the number of grids represents the computational sum of the model [21,54]. In comparison with using the $5 \mathrm{~km}$ resolution meteorological data for the regional potential productivity simulation, the application of appropriate spatial resolution can effectively reduce the number of grids (Figure 7). Moreover, in the region in the eastern research area, where the spatial heterogeneity of the landforms is relatively weak, as the threshold of scale effect index $S$ increases, the spatial resolution of the data changes to $160 \mathrm{~km}$, and the number of grids decreases significantly; in the SWS with relatively strong spatial heterogeneity of landforms, the spatial resolution is maintained at $5 \mathrm{~km}$, and the magnitude of the variation in the grid number is relatively small (Figures 6 and 7). 


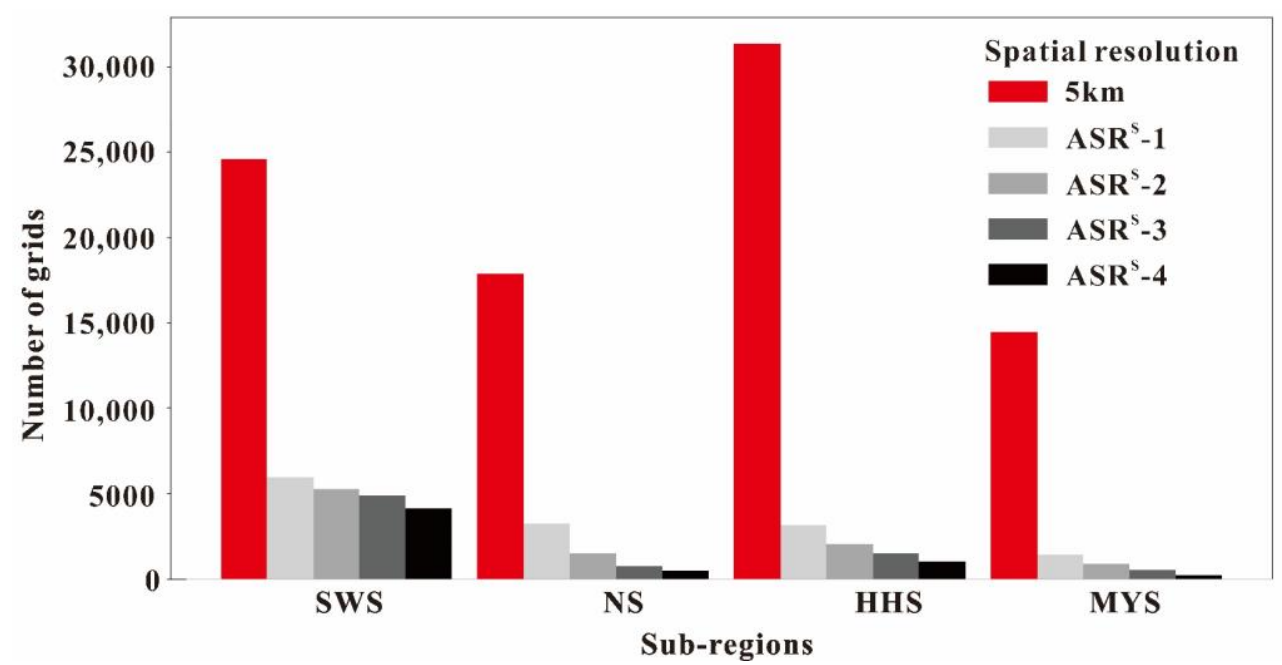

Figure 7. Number of simulation grids with appropriate spatial resolution in the sub-regions of the research area: southwest winter wheat sub-region (SWS), north winter wheat sub-region (NS), Huang-Huai winter wheat sub-region (HHS), and middle-lower reaches of the Yangzi River winter wheat sub-region (MYS).

Meanwhile, in this study, we selected the average value as the accuracy index to evaluate the use of the appropriate spatial resolution for the simulation [16,21]. In comparison with the average of simulation results with a spatial resolution of $5 \mathrm{~km}$, the average of simulation results with appropriate spatial resolutions of $\mathrm{ASR}^{S}-1, \mathrm{ASR}^{S}-2, \mathrm{ASR}^{S}-3$, and $\mathrm{ASR}^{S}-4$ does not change considerably within a certain range, and the lowest absolute difference from the average of simulation results with a $5 \mathrm{~km}$ resolution can reach $5.2 \mathrm{~kg} \mathrm{ha}^{-1}$ year $^{-1}$ (Table 2). By using the appropriate spatial resolution for the simulation, we can ensure simulation accuracy, but for the SWS with relatively strong spatial heterogeneity of landforms, the average exhibits a trend of increasing as the threshold of scale effect index $S$ increases.

Table 2. Absolute difference between the average simulation results for the grids of different appropriate spatial resolutions and the average simulation results for the grid with a resolution of $5 \mathrm{~km}$.

\begin{tabular}{|c|c|c|c|c|c|c|}
\hline & \multirow{2}{*}{ Regions } & \multicolumn{5}{|c|}{ Spatial Resolution } \\
\hline & & $5 \mathrm{~km}$ & $\mathrm{ASR}^{S}-1$ & $\mathrm{ASR}^{S}-2$ & $\mathrm{ASR}^{S}-3$ & $\mathrm{ASR}^{S}-4$ \\
\hline \multirow{5}{*}{$\begin{array}{c}\text { Mean } \\
\left(\mathrm{kg} \mathrm{ha}^{-1} \text { year }^{-1}\right)\end{array}$} & Research area & 8052.2 & 8132.5 & 8078.0 & 8037.3 & 8047.0 \\
\hline & SWS & 7583.0 & 7752.7 & 7905.2 & 7963.1 & 8048.4 \\
\hline & NS & 8758.3 & 8901.4 & 8706.6 & 8492.2 & 8288.8 \\
\hline & HHS & 8220.0 & 8427.0 & 8410.7 & 8266.4 & 7957.8 \\
\hline & MYS & 7641.1 & 7711.2 & 7821.2 & 7836.6 & 7765.2 \\
\hline \multirow{5}{*}{$\begin{array}{c}\mathrm{Abs}^{\mathrm{a}} \\
\left(\mathrm{kg} \mathrm{ha}^{-1} \text { year }^{-1}\right)\end{array}$} & Research area & - & 80.3 & 25.8 & 14.9 & 5.2 \\
\hline & SWS & - & 169.7 & 322.2 & 380.1 & 465.4 \\
\hline & NS & - & 143.1 & 51.7 & 266.1 & 469.5 \\
\hline & HHS & - & 207 & 190.7 & 46.4 & 262.2 \\
\hline & MYS & - & 70.1 & 180.1 & 195.5 & 124.1 \\
\hline
\end{tabular}

a Abs, the absolute difference between the appropriate spatial resolution of meteorological data used in different sub-regions and the average simulation results with a $5 \mathrm{~km}$ resolution.

Previous studies that obtained the appropriate spatial resolution of model input data as a single value [21], such as $100 \mathrm{~km}[16,19]$. In this study, we used the multi-spatial resolution grid fusion method to optimize the data of unified spatial resolution and collect the appropriate spatial resolutions required for the regional potential productivity simulation on the same map (Figure 6). This approach can truly reflect the spatial distribution of resolution for meteorological data under different terrain 
backgrounds and solves the problem that the unified spatial resolution is not applicable to regions with relatively large differences in the spatial heterogeneity of landforms [19]. Therefore, it can satisfy the demand of various sub-regions in the winter wheat area of China at different appropriate spatial resolutions.

\subsection{Selection of the Appropriate Spatial Resolution Based on the Spatial Heterogeneity of Landforms}

Previous studies indicated that meteorological data are significantly affected by terrain, and we can use the spatial heterogeneity of landforms to reflect the scale effect of simulation results for the regional potential productivity $[15,55,56]$. In the region where the spatial heterogeneity of landforms is stronger, the larger the sill value $\varsigma$ of the DEM semi-variogram is, the larger the scale effect index $S$ will be. The sill value and scale effect index exhibit a similar trend of spatial distribution (Figures 5 and 8 ), and there is a significant correlation (Figure 9). As the spatial resolution decreases, the fitting relationship between the sill value $\varsigma$ of the DEM semi-variogram and the scale effect index $S$ gradually weakens (Figure 9). By using the fitting relationship $\ln (S) \sim \ln (\varsigma)$, we obtained the threshold corresponding to the sill value $\varsigma$ of the DEM semi-variogram according to the threshold of the scale effect index $S$ (Table 3) and obtained the appropriate spatial resolution of the meteorological data based on the threshold for the sill value $\varsigma$ of the DEM semi-variogram (Figure 10).

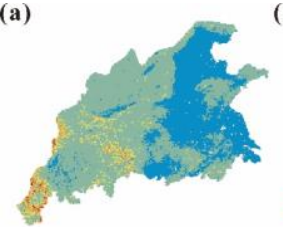

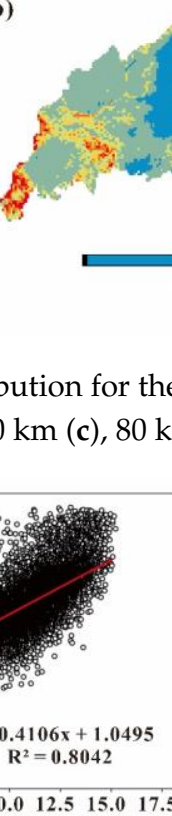

(c)
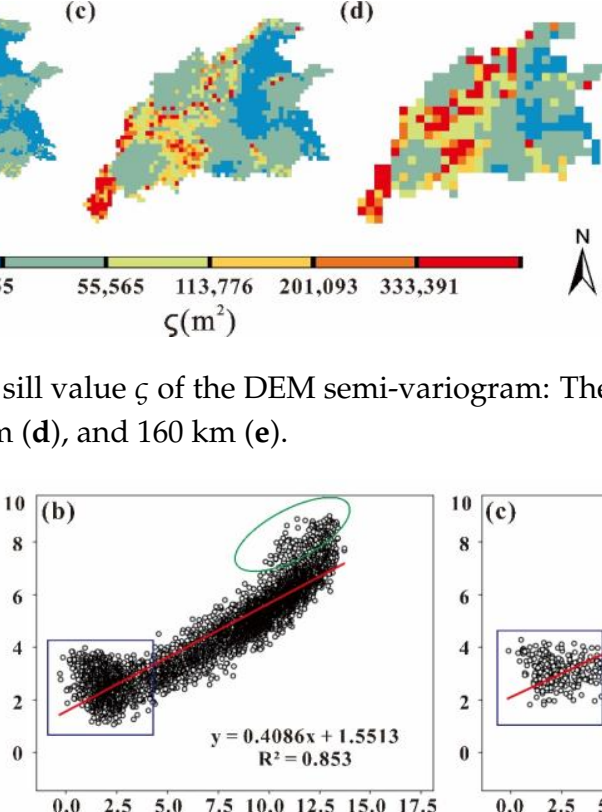

(e)

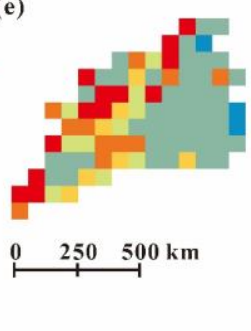

Figure 8. Spatial distribution for the sill value $\varsigma$ of the DEM semi-variogram: The spatial resolution is $10 \mathrm{~km}(\mathbf{a}), 20 \mathrm{~km}(\mathbf{b}), 40 \mathrm{~km}(\mathbf{c}), 80 \mathrm{~km}(\mathbf{d})$, and $160 \mathrm{~km}(\mathbf{e})$.
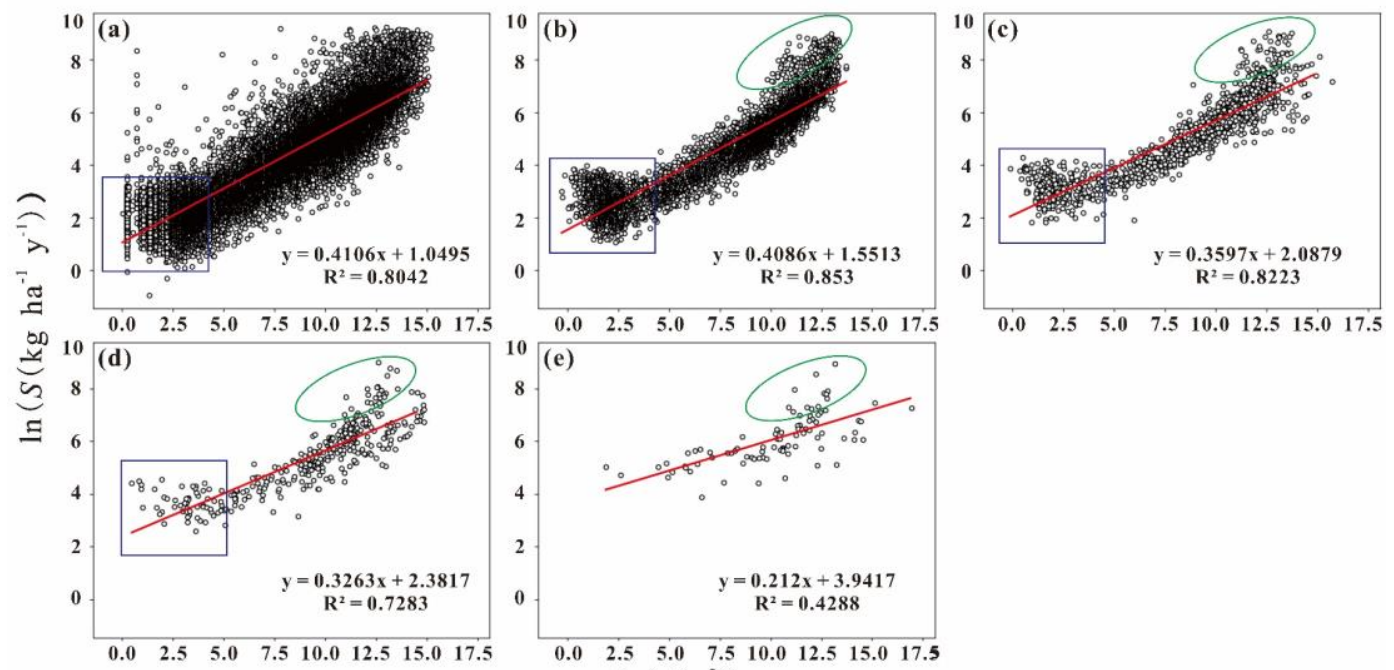

Figure 9. Fitting relationship between scale effect index $S$ and the sill value $\varsigma$ of the DEM

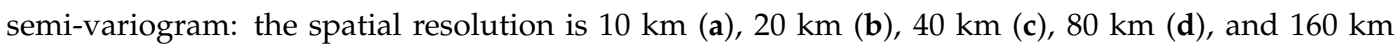
(e). $\ln (\varsigma)$, natural logarithmic function. 
Table 3. Threshold setting for the sill value $\varsigma$ of the DEM semi-variogram.

\begin{tabular}{cccccc}
\hline \multirow{2}{*}{$\begin{array}{c}\text { Thresholds of } \boldsymbol{S}^{\mathbf{a}} \\
\mathbf{~ k g ~ h a ~}^{\mathbf{1}} \text { year }^{-\mathbf{1}} \mathbf{)}\end{array}$} & $\mathbf{5} \mathbf{~} \mathbf{~} \mathbf{T h}$ & $\mathbf{2 0} \mathbf{~ k m}$ & $\mathbf{4 0} \mathbf{~ k m}$ & $\mathbf{8 0} \mathbf{~ k m}$ & $\mathbf{1 6 0} \mathbf{~ k m}$ \\
\cline { 2 - 6 } & 5766 & 1762 & 1095 & 911 & 23 \\
200 & 31,189 & 9608 & 7520 & 7619 & 601 \\
300 & 83,727 & 25,918 & 23,214 & 26,399 & 4017 \\
400 & 168,714 & 52,406 & 51,652 & 63,750 & 15,815 \\
\hline
\end{tabular}

a Thresholds of $S$ reflect the threshold of scale effect index $S .{ }^{\text {b }}$ Thresholds of $\zeta$ reflect the threshold for the sill value $\varsigma$ of the DEM semi-variogram.

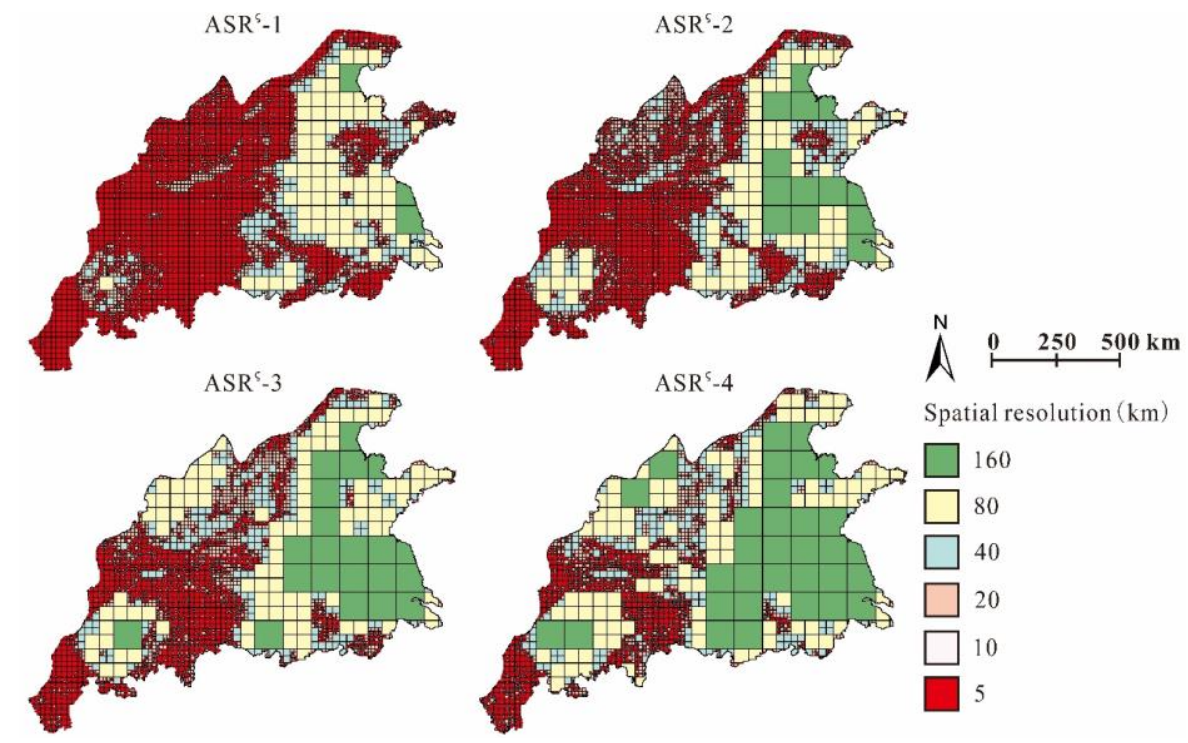

Figure 10. Appropriate spatial resolution of meteorological data for the regional potential productivity simulation determined based on the sill value $\varsigma$ of the DEM semi-variogram.

By comparing the distribution of appropriate spatial resolution of meteorological data obtained by two methods, the Kappa coefficient in the SWS, HHS, and MYS was between 0.4 and 0.7 at a confidence level of $\alpha=0.05$. This indicates that the distribution of appropriate resolution from the two schemes has moderate, but not high, consistency (Figure 11 and Table 4) [57]. This is primarily because the spatial heterogeneity of meteorological factors in the research area cannot be completely expressed with the spatial heterogeneity of landforms, and the meteorological factors are still affected by the factors of longitude, latitude, and distance from the sea [58,59]. Furthermore, the scale of spatial heterogeneity for the terrain data and the spatial heterogeneity of the meteorological data is not united [59]. When the scale effect index $S$ is relatively small, the $\ln (S) \sim \ln (\varsigma)$ fitting relationship exhibits an aggregation phenomenon (Figure 9, rectangle); when the scale effect index $S$ is relatively large, the $\ln (S) \sim \ln (\varsigma)$ fitting relationship exhibits a saturation phenomenon (Figure 9, ellipse). With the spatial resolution of $20 \mathrm{~km}$ as an example, when $\ln (\varsigma)<4$, there is no significant correlation between $\ln (S)$ and $\ln (\varsigma)$ for the NS, HHS, and MYS (Figure 12b-d). At this popint, the sill value of the DEM semi-variogram is $\varsigma<e^{4} \approx 55 \mathrm{~m}^{2}$, which indicates that this region is primarily distributed in the eastern plains region of research area (Figure 8), and the spatial heterogeneity of the landform is weak. Therefore, for the regions with relatively weak spatial heterogeneity of landforms, the application of terrain cannot reflect the scale effect for the simulation results of potential productivity; meanwhile, when $\ln (\varsigma)>10$, as $\ln (S)$ increases, $\ln (\varsigma)$ no longer increases according to the fitting relationship (Figure 12, ellipse). In these regions, the variation range of the topographic semi-variogram is smaller than the spatial resolution of the grid at more than $70 \%$ of the grid points (Figure 13). That is, when the spatial variation of landforms occurs in a relatively small range, the spatial variation of landforms cannot reflect the scale 
effect for the simulation results of potential productivity and cannot guide the selection of appropriate spatial resolution in this region.
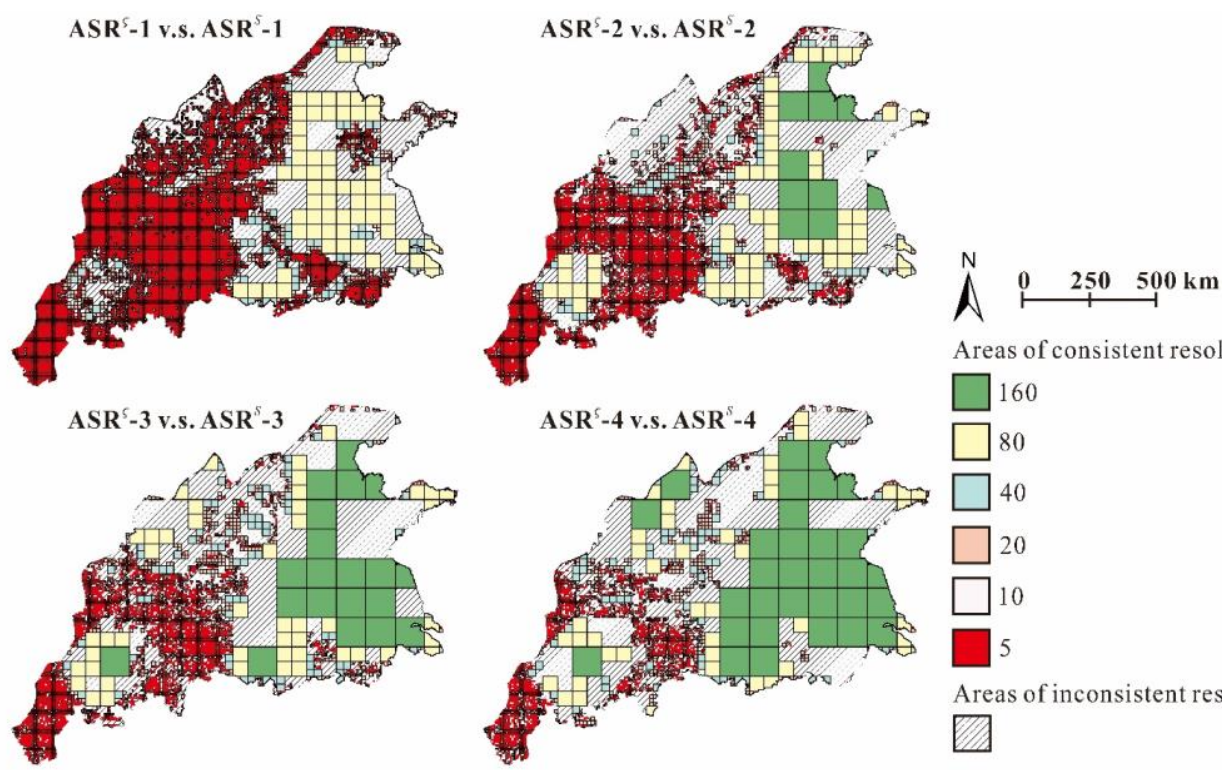

Areas of consistent resolutions $(\mathrm{km})$

$\square 160$
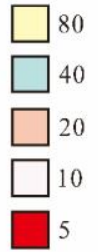

Areas of inconsistent resolutions

Figure 11. Contrast of the distribution of appropriate spatial resolution of the meteorological data obtained based on the scale effect index $S$ and the sill value $\varsigma$ of the DEM semi-variogram.

Table 4. Kappa consistency test of the appropriate spatial resolution obtained by the threshold of scale effect index $S$ and the threshold for the sill value $\varsigma$ of the DEM semi-variogram: Southwest winter wheat sub-region (SWS), north winter wheat sub-region (NS), Huang-Huai winter wheat sub-region (HHS), and middle-lower reaches of the Yangzi River winter wheat sub-region (MYS).

\begin{tabular}{|c|c|c|c|c|}
\hline \multirow{2}{*}{ Regions } & \multicolumn{4}{|c|}{ Kappa Coefficient $(p<0.05)$} \\
\hline & $\operatorname{ASR}^{S}-1$ vs. $\operatorname{ASR}^{S}-1$ & $\mathrm{ASR}^{S}-2$ vs. $\mathrm{ASR}^{S}-2$ & $\operatorname{ASR}^{S}-3$ vs. $\operatorname{ASR}^{S}-3$ & $\mathrm{ASR}^{S}-4$ vs. $\mathrm{ASR}^{S}-4$ \\
\hline Research area & 0.577 & 0.521 & 0.524 & 0.516 \\
\hline SWS & 0.613 & 0.618 & 0.562 & 0.438 \\
\hline NS & 0.3 & 0.253 & 0.238 & 0.322 \\
\hline HHS & 0.574 & 0.506 & 0.466 & 0.521 \\
\hline MYS & 0.55 & 0.463 & 0.635 & 0.566 \\
\hline
\end{tabular}
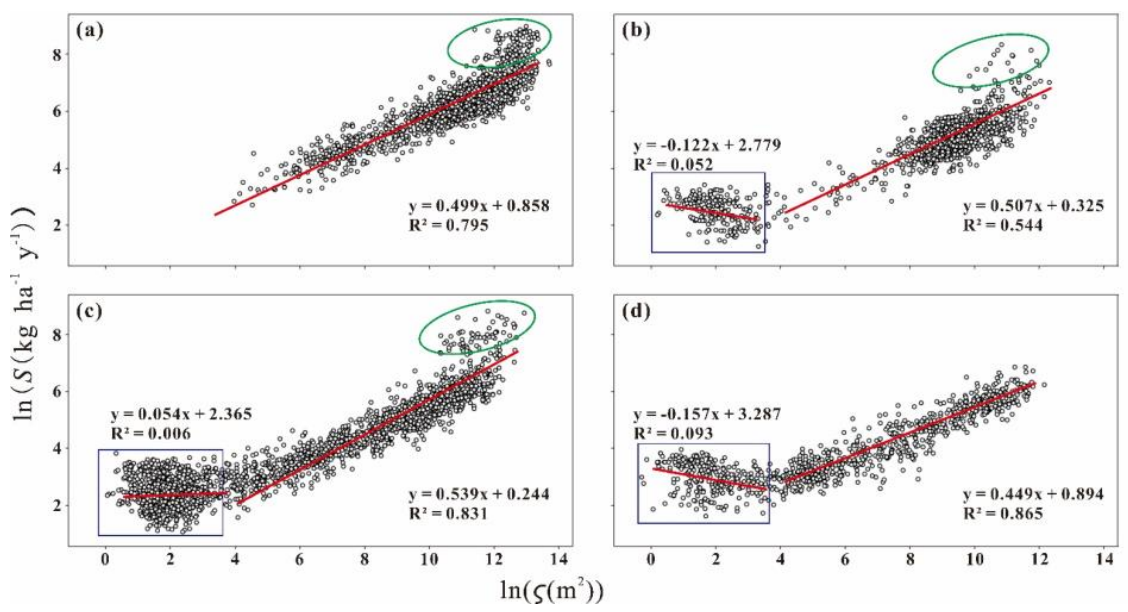

Figure 12. Fitting relationship between the scale effect index $S$ and the sill value $\varsigma$ of the DEM semi-variogram in different sub-regions when the spatial resolution is $20 \mathrm{~km}$ : Southwest winter wheat sub-region (SWS) (a), north winter wheat sub-region (NS) (b), Huang-Huai winter wheat sub-region (HHS) (c), and middle-lower reaches of the Yangzi River winter wheat sub-region (MYS) (d). 


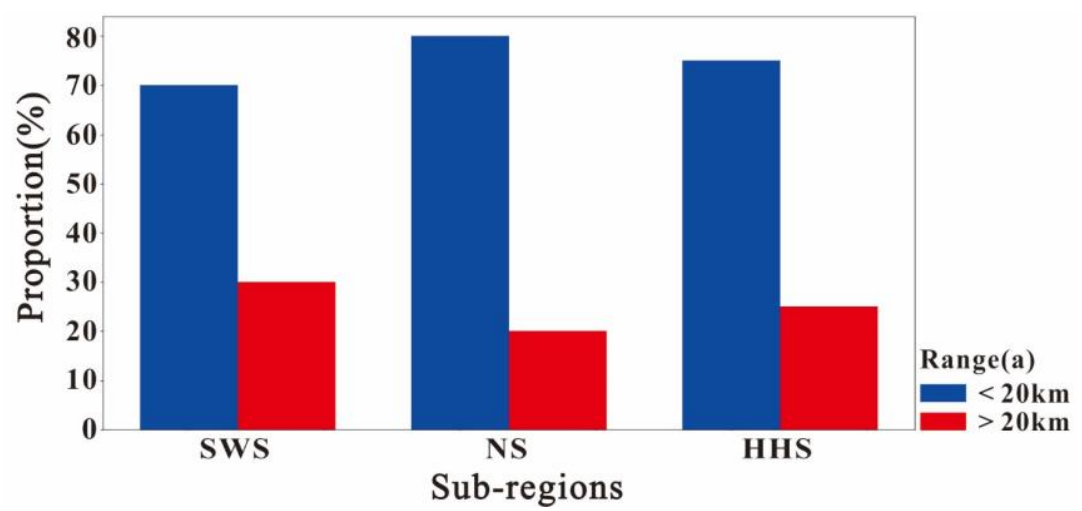

Figure 13. With the spatial resolution of $20 \mathrm{~km}$ as an example, the distribution of ranges for the DEM semi-variogram in different sub-regions: southwest winter wheat sub-region (SWS), north winter wheat sub-region (NS), and Huang-Huai winter wheat sub-region (HHS).

In this study, we adopted spatial semi-variogram analysis to describe the spatial heterogeneity of natural factors with an isotropic model $[60,61]$. However, semi-variogram analysis relies on the selected theoretical semi-variogram model as well as the direction, and the incorrect selection of the theoretical semi-variogram model or ignorance of anisotropy can lead to results for the characteristic spatial variation of landforms that are difficult to interpret. Meanwhile, the lag distance, range, and sill value in the semi-variogram analysis often affect each other, causing unstable analysis results and therefore affecting the results of this study [62]. It is important to combine multiple parameters for the semi-variogram analysis to obtain more reliable results [63]. In addition, although the appropriate spatial resolution obtained in this study can significantly reduce the computational load of regional potential productivity simulation under the requirement of ensuring accuracy, it is limited by the resolution sequence constructed in this study rather than the so-called global optimum spatial resolution. Meanwhile, there is not a scale (resolution) that is appropriate for the studies on all the geographic processes involved in the regional application of the crop model [64]. Its suitability is manifested by the matching of the crop growth simulation model and virtual geographical environment representation with respect to the domains of issue, structure, and dimension. By selecting the appropriate resolution from the limited resolution sequence, we can reduce the influence of resolution on the accuracy and efficiency of simulation results.

Moreover, this study is constrained to potential productivity simulation with WheatGrowth model. And land productivity simulation, rather than potential productivity simulation, is more vulnerable to the variability of soil $[16,65]$. Besides, it is also found that the uncertainties of radiation and precipitation have little influence over the regional yield forecast with World Food Studies (WOFOST) crop simulation model [21]. These issues indicate the range of model limitations and specificities of crop model applications [66], and should be focused and studied in our future researches.

\section{Conclusions}

In this study, we took the winter wheat region of China as the research area and simulated the regional potential productivity from 2000 to 2009 based on the WheatGrow model by constructing meteorological data with six spatial resolutions. We analyzed the influence of the scale effect for the meteorological data on the simulation of potential productivity in the winter wheat region of China and obtained the appropriate spatial resolution of meteorological data for the regional potential productivity simulation. Moreover, we clarified the feasibility of using the topographic features to obtain the appropriate spatial resolution of meteorological data required for the simulation of potential productivity in the winter wheat region of China. (1) Based on the threshold of the scale effect index, through multi-spatial resolution grid data fusion, we can effectively obtain the appropriate spatial resolution of the meteorological data required by the regional potential productivity simulation in 
the winter wheat area of China. The spatial resolution of data needed for the eastern plains area is relatively low, and it is concentrated at $80 \mathrm{~km}$ and $160 \mathrm{~km}$; the spatial resolution of data needed for the western and southwestern mountainous and hilly regions is relatively high, and it is concentrated at $5 \mathrm{~km}$. (2) The stronger the spatial heterogeneity of the topographic environment and meteorological environment is, the higher the spatial resolution of meteorological data required for the regional potential productivity simulation, and vice versa. (3) By using the appropriate spatial resolution of meteorological data to conduct the regional potential productivity simulation, we can ensure simulation accuracy, reduce the amount of regional simulation units, increase the efficiency of regional simulation, and improve the capability of explaining the spatial morphology and differences in the results of simulation of the regional potential productivity. (4) Although the application of the sill value for the DEM semi-variogram can guide the selection of the appropriate spatial resolution for the meteorological data, in the regions with relatively weak spatial heterogeneity of landforms on the eastern plains or the small-scale regions with strong spatial variation of landforms in the southwest, it cannot sufficiently reflect the scale effect for the simulation results of potential productivity. Therefore, the application is restricted to using the single heterogeneity index of landforms to obtain the appropriate spatial resolution of meteorological data required for the regional potential productivity simulation of winter wheat in China and needs further improvement.

Author Contributions: Conceptualization, X.Z. and Y.Z.; Funding acquisition, W.C. and Y.Z.; Methodology, X.Z. and H.X.; Resources, L.J.; Software, H.X., L.J. and J.Z.; Visualization, W.Z. and X.Q.; Writing一original draft, X.Z. and W.Z.; Writing-review \& editing, Y.T.

Funding: This research is supported by grants from the National Key R\&D Program of China (No. 2017YFD0301203) and the Jiangsu Province Key Technologies R\&D Program (No. BE2016375).

Conflicts of Interest: The authors declare no conflict of interest.

\section{References}

1. Lloyd, T.E. Crop Evolution, Adaptation and Yield; Cambridge University Press: Cambridge, UK, 1996.

2. Gustafson, D.I.; Jones, J.W.; Porter, C.H.; Hyman, G.; Edgerton, M.D.; Gocken, T.; Shryock, J.; Doane, M.; Budreski, K.; Stone, C. Climate adaptation imperatives: Untapped global maize yield opportunities. Int. J. Agric. Sustain. 2014, 12, 471-486. [CrossRef]

3. Ponisio, L. Diversification, Yield and a New Agricultural Revolution: Problems and Prospects. Sustainability 2016, 8, 1118. [CrossRef]

4. Wang, H.; Chen, F.; Shi, Q.; Fan, S.; Chu, Q. Analysis of factors on impacting potential productivity of winter wheat in Huanghuaihai agricultural area over 30 years. Trans. Chin. Soc. Agric. Eng. 2010, 26, 90-95.

5. FAO. Report on the Agro-Ecological Zones Project; Methodology and Results for Africa; World Soil Resources Report 48/1; FAO: Rome, Italy, 1978.

6. Rosenzweig, C.; Elliott, J.; Deryng, D.; Ruane, A.C.; Müller, C.; Arneth, A.; Boote, K.J.; Folberth, C.; Glotter, M.; Khabarov, N. Assessing agricultural risks of climate change in the 21st century in a global gridded crop model intercomparison. Proc. Natl. Acad. Sci. USA 2014, 111, 3268-3273. [CrossRef] [PubMed]

7. Tabasum, S.; Nain, A.S.; Khan, I. Assessment of Production Potential of Wheat Using CERES-Wheat Crop Model. Ann. Agric. Biol. Res. 2006, 11, 161.

8. Li, J.; Wang, L.X.; Shao, M.A. Simulation of wheat potential productivity on Loess Plateau region of China. J. Nat. Resour. 2001, 16, 161-165.

9. Wang, T.; Lü, C.; Yu, B. Assessing the potential productivity of winter wheat using WOFOST in the Beijing-Tianjin-Hebei Region. J. Nat. Resour. 2010, 25, 475-487.

10. Lu, C.; Lan, F. Winter wheat yield potentials and yield gaps in the North China Plain. Field Crops Res. 2013, 143, 98-105. [CrossRef]

11. Lv, Z.; Liu, X.; Cao, W.; Zhu, Y. Climate change impacts on regional winter wheat production in main wheat production regions of China. Agric. For. Meteorol. 2013, 171, 234-248. [CrossRef]

12. Liu, T.; Cao, W.; Luo, W.; Wang, S.; Yin, J. A simulation model of photosynthetic production and dry matter accumulation in wheat. J. Triticeae Crops 2001, 21, 26-30. 
13. Basu, S.K.; Kumar, N. Modelling and Simulation of Diffusive Processes; Springer International: Cham, Switzerland, 2016.

14. Olesen, J.E.; Bocher, P.K.; Jensen, T. Comparison of scales of climate and soil data for aggregating simulated yields of winter wheat in Denmark. Agric. Ecosyst. Environ. 2000, 82, 213-228. [CrossRef]

15. Zhao, G.; Siebert, S.; Enders, A.; Rezaei, E.E.; Yan, C.; Ewert, F. Demand for multi-scale weather data for regional crop modeling. Agric. For. Meteorol. 2015, 200, 156-171. [CrossRef]

16. Eyshi Rezaei, E.; Siebert, S.; Ewert, F. Impact of data resolution on heat and drought stress simulated for winter wheat in Germany. Eur. J. Agron. 2015, 65, 69-82. [CrossRef]

17. Van Bussel, L.G.J.; Müller, C.; van Keulen, H.; Ewert, F.; Leffelaar, P.A. The effect of temporal aggregation of weather input data on crop growth models' results. Agric. For. Meteorol. 2011, 151, 607-619. [CrossRef]

18. Zhao, G.; Hoffmann, H.; van Bussel, L.G.J.; Enders, A.; Specka, X.; Sosa, C.; Yeluripati, J.; Tao, F.; Constantin, J.; Raynal, H.; et al. Effect of weather data aggregation on regional crop simulation for different crops, production conditions, and response variables. Clim. Res. 2015, 65, 141-157. [CrossRef]

19. Van Bussel, L.G.J.; Ewert, F.; Leffelaar, P.A. Effects of data aggregation on simulations of crop phenology. Agric. Ecosyst. Environ. 2011, 142, 75-84. [CrossRef]

20. Zhao, G.; Hoffmann, H.; Yeluripati, J.; Xenia, S.; Nendel, C.; Coucheney, E.; Kuhnert, M.; Tao, F.; Constantin, J.; Raynal, H.; et al. Evaluating the precision of eight spatial sampling schemes in estimating regional means of simulated yield for two crops. Environ. Modell. Softw. 2016, 80, 100-112. [CrossRef]

21. De Wit, A.J.W.; Boogaard, H.L.; van Diepen, C.A. Spatial resolution of precipitation and radiation: The effect on regional crop yield forecasts. Agric. For. Meteorol. 2005, 135, 156-168. [CrossRef]

22. Easterling, W.E.; Weiss, A.; Hays, C.J.; Mearns, L.O. Spatial scales of climate information for simulating wheat and maize productivity: The case of the US Great Plains. Agric. For. Meteorol. 1998, 90, 51-63. [CrossRef]

23. Van Oijen, M.; Thomson, A.; Ewert, F. Spatial upscaling of process-based vegetation models: An overview of common methods and a case-study for the UK. In Proceedings of the StatGIS 2009, Milos, Greece, 17-19 June 2009.

24. Zheng, J.; Yin, Y.; Bingyuan, L.I. A New Scheme for Climate Regionalization in China. Acta Geogr. Sin. 2010, 65, 3-12.

25. Zhao, G. Study on Chinese wheat planting regionalization (II). J. Triticeae Crops 2010, 30, 1140.

26. Liu, T.; Cao, W.; Luo, W. Calculation of physiological development time and prediction of development stages after heading. Acta Tritical Crops 2000, 20, 29-34.

27. Liu, B.; Liu, L.; Asseng, S.; Zou, X.; Li, J.; Cao, W.; Zhu, Y. Modelling the effects of heat stress on post-heading durations in wheat: A comparison of temperature response routines. Agric. For. Meteorol. 2016, 222, 45-58. [CrossRef]

28. Yan, M.; Cao, W.; Luo, W.; Jiang, H. A mechanistic model of phasic and phenological development of wheat. I. Assumption and description of the model. Chin. J. Appl. Ecol. 2000, 11, 355.

29. Cao, W.; Moss, D.N. Modelling phasic development in wheat: A conceptual integration of physiological components. J. Agric. Sci. 1997, 129, 163-172. [CrossRef]

30. Liu, T.; Cao, W.; Luo, W.; Wang, S.; Guo, W.; Zou, W.; Zhou, Q. Quantitative simulation on dry matter partitioning dynamic in wheat organs. J. Triticeae Crops 2001, 21, 25-31.

31. Zhu, Y.; Liu, L.; Liu, B. WheatGrow: A simulation model for predicting growth and productivity in wheat. In Proceedings of the Workshop on Modeling Wheat Response to High Temperature, Texcoco, Mexico, 19-21 June 2013.

32. Pan, J.; Zhu, Y.; Cao, W. Modeling plant carbon flow and grain starch accumulation in wheat. Field Crop Res. 2007, 101, 276-284. [CrossRef]

33. Hu, J.; Cao, W.; Jiang, D.; Luo, W. Quantification of water stress factor for crop growth simulation I. Effects of drought and waterlogging stress on photosynthesis, transpiration and dry matter partitioning in winter wheat. Acta Agron. Sin. 2004, 30, 315-320.

34. Zhuang, H.Y.; Cao, W.X.; Jiang, S.X.; Wang, Z. Simulation on nitrogen uptake and partitioning in crops. Syst. Sci Compr. Stud. Agric. 2004, 20, 5-8.

35. Cao, W.; Liu, T.; Luo, W.; Wang, S.; Pan, J.; Guo, W. Simulating Organ Growth in Wheat Based on the Organ-Weight Fraction Concept. Plant Prod. Sci. 2002, 5, 248-256. [CrossRef] 
36. Huang, Y.; Zhu, Y.; Wang, H.; Yao, X.; Cao, W.; Hannaway, D.B.; Tian, Y. Predicting winter wheat growth based on integrating remote sensing and crop growth modeling techniques. Acta Ecol. Sin. 2011, 31, 1073-1084.

37. Liu, S.; Mo, X.; Lin, Z.; Xu, Y.; Ji, J.; Gang, W.; Richey, J. Crop yield responses to climate change in the Huang-Huai-Hai Plain of China. Agric. Water Manag. 2010, 97, 1195-1209. [CrossRef]

38. Van Ittersum, M.K.; Cassman, K.G.; Grassini, P.; Wolf, J.; Tittonell, P.; Hochman, Z. Yield gap analysis with local to global relevance-A review. Field Crops Res. 2013, 143, 4-17. [CrossRef]

39. Nátr, L. Crop Evolution, Adaptation and Yield. Photosynthetica 1998, 38, 275-276. [CrossRef]

40. Zhang, S.Y.; Zhang, X.H.; Qiu, X.L.; Tang, L.; Zhu, Y.; Cao, W.X.; Liu, L.L. Quantifying the spatial variation in the potential productivity and yield gap of winter wheat in China. J. Integr. Agric. 2017, 16, 845-857. [CrossRef]

41. Hutchinson, M.F. Interpolating mean rainfall using thin plate smoothing splines. Int. J. Geogr. Inf. Syst. 1995, 9, 385-403. [CrossRef]

42. Malebajoa, M. Climate Change Impacts on Crop Yields and Adaptive Measures for Agricultural Sector in the Lowlands of Lesotho; Lunds Universitets Naturgeografiska Institution-Seminarieuppsatser: Lund, Sweden, 2010.

43. Farr, T.G.; Rosen, P.A.; Caro, E.; Crippen, R.; Duren, R.; Hensley, S.; Kobrick, M.; Paller, M.; Rodriguez, E.; Roth, L. The Shuttle Radar Topography Mission. Rev. Geophys. 1998, 45, 361. [CrossRef]

44. Wu, S.; Li, J.; Huang, G.H. A study on DEM-derived primary topographic attributes for hydrologic applications: Sensitivity to elevation data resolution. Appl. Geogr. 2008, 28, 210-223. [CrossRef]

45. Moellering, H.; Tobler, W. Geographical Variances. Geogr. Anal. 1972, 4, 34-50. [CrossRef]

46. Godwin, R.J.; Miller, P.C.H. A Review of the Technologies for Mapping Within-field Variability. Biosyst. Eng. 2003, 84, 393-407. [CrossRef]

47. Li, Y.; Yang, X.; Cai, H.; Xiao, L.; Xu, X.; Liu, L. Topographical Characteristics of Agricultural Potential Productivity during Cropland Transformation in China. Sustainability 2014, 7, 96-110. [CrossRef]

48. Li, H.; Reynolds, J.F. On Definition and Quantification of Heterogeneity. Oikos 1995, 73, 280-284. [CrossRef]

49. Oliver, M.A.; Webster, R. A tutorial guide to geostatistics: Computing and modelling variograms and kriging. CATENA 2014, 113, 56-69. [CrossRef]

50. Robeson, S.M. Spherical Methods for Spatial Interpolation: Review and Evaluation. Cartogr. Geogr. 1997, 24, 3-20. [CrossRef]

51. Goovaerts, P. Geostatistical approaches for incorporating elevation into the spatial interpolation of rainfall. J. Hydrol. 2000, 228, 113-129. [CrossRef]

52. Isaaks, E.H.; Srivastava, R.M. An Introduction to Applied Geostatistics; Oxford University Press: Oxford, NY, USA, 1989; p. 147.

53. Pebesma, E.J. Multivariable geostatistics in S: The gstat package. Comput. Geosci. 2004, 30, 683-691. [CrossRef]

54. Villoria, N.B.; Elliott, J.; Müller, C.; Shin, J.; Zhao, L.; Song, C. Rapid aggregation of global gridded crop model outputs to facilitate cross-disciplinary analysis of climate change impacts in agriculture. Environ. Model. Softw. 2016, 75, 193-201. [CrossRef]

55. Oliphant, A.J.; Spronkensmith, R.A.; Sturman, A.P.; Owens, I.F. Spatial Variability of Surface Radiation Fluxes in Mountainous Terrain. J. Appl. Meteorol. 2003, 42, 113-128. [CrossRef]

56. Pan, Y.; Gong, D.; Deng, L.; Li, J.; Gao, J. Smart distance searching-based and DEM-informed interpolation of surface air temperature in China. Acta Geogr. Sin. 2004, 3, 007.

57. Viera, A.J.; Garrett, J.M. Understanding interobserver agreement: The kappa statistic. Fam. Med. 2005, 37, 360-363. [PubMed]

58. Holton, J.R. An Introduction to Dynamic Meteorology. Am. J. Phys. 2004, 41, 752-754. [CrossRef]

59. Gubler, S.; Fiddes, J.; Keller, M.; Gruber, S. Scale-dependent measurement and analysis of ground surface temperature variability in alpine terrain. Cryosphere Discuss. 2011, 5, 431-443. [CrossRef]

60. Beek, C.Z.V.D.; Leijnse, H.; Torfs, P.J.J.F.; Uijlenhoet, R. Climatology of daily rainfall semivariance in the Netherlands. Hydrol. Earth Syst. Sci. 2011, 15, 171-183. [CrossRef]

61. Tarnavsky, E.; Garrigues, S.; Brown, M.E. Multiscale geostatistical analysis of AVHRR, SPOT-VGT, and MODIS global NDVI products. Remote Sens. Environ. 2008, 112, 535-549. [CrossRef]

62. Zhang, X.H.; Zuo, W.J.; Zhao, S.L.; Jiang, L. Chen, L.H.; Zhu, Y. Uncertainty in Upscaling In Situ Soil Moisture Observations to Multiscale Pixel Estimations with Kriging at the Field Level. Int. J. Geo-Inf. 2018, 7, 33. [CrossRef] 
63. Gertner, G.; Wang, G. Appropriate Plot Size and Spatial Resolution for Mapping Multiple Vegetation Types. Photogramm. Eng. Remote Sens. 2001, 67, 575-584.

64. Chave, J.; Levin, S. Scale and Scaling in Ecological and Economic Systems. Environ. Resour. Econ. 2003, 26, 527-557. [CrossRef]

65. Hoffmann, H.; Zhao, G.; Asseng, S.; Bindi, M.; Biernath, C. Impact of spatial soil and climate input data aggregation on regional yield simulations. PLOS ONE 2016, 11, e0151782. [CrossRef] [PubMed]

66. Taru, P.; Kersebaum, K.C.; Angulo, C.; Hlavinka, P.; Moriondo, M.; Olesen, J.E.; Patil, R.H.; Ruget, F.; Rumbaur, C.; Takáč, M.; et al. Simulation of winter wheat yield and its variability in different climates of Europe: A comparison of eight crop growth models. Eur. J. Agron. 2011, 35, 103-114.

2018 by the authors. Licensee MDPI, Basel, Switzerland. This article is an open access article distributed under the terms and conditions of the Creative Commons Attribution (CC BY) license (http://creativecommons.org/licenses/by/4.0/). 